Hélder Pordeus Muniz ${ }^{1}$

Jussara Brito ${ }^{2}$

Kátia Reis de Souza ${ }^{2}$

Milton Athayde ${ }^{3}$

Marianne Lacomblez ${ }^{4}$

\section{Ivar Oddone e sua contribuição para o campo da Saúde do Trabalhador no Brasil}

\author{
Ivar Oddone and his contribution to Worker's Health in Brazil
}

${ }^{1}$ Departamento de Psicologia, Universidade Federal Fluminense. Niterói, RJ, Brasil.

${ }^{2}$ Centro de Estudos em Saúde do Trabalhador e Ecologia Humana, Escola Nacional de Saúde Pública, Fundação Oswaldo Cruz. Rio de Janeiro, RJ, Brasil.

${ }^{3}$ Instituto de Psicologia, Universidade do Estado do Rio de Janeiro. Rio de Janeiro, RJ, Brasil.

${ }^{4}$ Centro de Psicologia, Universidade do Porto. Porto, Portugal.

Contato:

Hélder Pordeus Muniz

E-mail:

heldermuniz@uol.com.br

O trabalho não foi subvencionado.

Os autores declaram não haver conflito de interesses.

\section{Resumo}

Este ensaio aborda as contribuições de Ivar Oddone e do Modelo Operário Italiano (MOI) de luta pela saúde para o desenvolvimento do campo da Saúde do Trabalhador, particularmente no Brasil. Primeiramente, faz-se um balanço das formas de incorporação do legado do MOI nos estudos e nas práticas de Saúde do Trabalhador. A seguir, apresenta-se a experiência de construção de cartografias de riscos industriais desenvolvida em região do sudeste da França. A terceira parte trata da concepção de "comunidade científica ampliada" e suas derivações. Ao final, discute-se a técnica de "instrução ao sósia" como um instrumento eficaz para a reapropriação, pelos trabalhadores, de suas estratégias de ação no trabalho, assim como para desenvolvê-las. Destaca-se que não se trata de incorporar esse patrimônio tal e qual foi utilizado na Itália, mas de explorar seus princípios e experimentações, considerando seu potencial de produção de ações coletivas e de fortalecimento de mobilizações já existentes. Sinaliza-se a atualidade do MOI, pois, apesar das tradicionais formas de luta dos trabalhadores estarem menos visíveis, a capacidade de recriação dos trabalhadores é um potencial em que se deve apostar.

Palavras-chave: saúde do trabalhador; comunidade científica ampliada; modelo operário italiano; condições de trabalho; mapa de risco.

\begin{abstract}
This essay discusses the contributions of both Ivar Oddone and the Italian Worker's struggle for health Model (IWM) for the development of the worker's health field, particularly in Brazil. It starts by revising the ways the IWM legacy was incorporated to the Worker's Health research and practices. Then, it presents the building of the industrial hazard mappings experience carried out in the Southeast of France. The third part deals with the concept of "expanded scientific community" and its derivations. Finally, it discusses the "instruction to the double" technique as an effective instrument for workers' re-appropriation of their strategies for action at work and for their implementation. The paper highlights that it is not a matter of incorporating the Italian experience, but of working out its principles and experiences, considering its potential power for instigating collective actions and for strengthening existing mobilizations. The paper points at the IWM up to date aspect: although the traditional ways of struggling are less evident, one can be sure of workers' recreating capacity.
\end{abstract}

Keywords: worker's health; expanded scientific community; Italian worker model; labor conditions; risk map. 


\section{Introdução}

O objetivo deste ensaio é discutir o legado de um coletivo de profissionais de saúde e militantes político-sindicais italianos - tendo entre sua liderança técnico-científica o médico e psicólogo Ivar Oddone e outros (dentre eles, Gastone Marri, Sandra Gloria, Alessandra Re, Gianni Briante). Esses cientistas ativistas, que se costuma associar ao Modelo Operário Italiano (MOI) de luta pela saúde (ou contra a nocividade, como denominavam na Itália), contribuíram de fato, significativamente, para o desenvolvimento do campo da Saúde do Trabalhador no Brasil e, ao mesmo tempo, para a imposição de um debate relativo à produção de conhecimentos neste domínio.

A escrita e a publicação deste ensaio estão afetadas pela ainda recente (ocorrida em 21 de novembro de 2011) morte de Oddone (1923-2011) ${ }^{6}$. A respeito dessa extraordinária figura, outro médico e militante destacado neste campo, e que também se foi, o brasileiro David Capistrano Filho, ao fazer a apresentação do livro Ambiente de trabalho: a luta dos trabalhadores pela saúde (ODDONE et al., $1986)^{7}$, ressaltou que o admirava por que ele reunia três qualidades: "sólida cultura, firme compromisso com os trabalhadores e agudo sentido de realidade, expresso na valorização da prática, da ação, do trabalho concreto" (CAPISTRANO FILHO, 1986, p. 7). Salientava que o patrimônio do MOI inspirou no Brasil vários empreendimentos no campo da Saúde do Trabalhador, como: comissões sindicais sobre saúde, programas municipais e regionais de Saúde do Trabalhador, entidades como o Departamento Intersindical de Estudos e Pesquisas de Saúde e dos Ambientes de Trabalho (Diesat), além da publicação de revistas, livros, jornais e panfletos.

Além disso, Capistrano Filho (1986) chamava atenção para os obstáculos que esse movimento ainda enfrentava no Brasil: o primeiro referia-se à "dificuldade de enraizamento dos sindicatos nas fábricas, nos locais de trabalho" (p. 8). Ora, a base inicial do MOI estava exatamente nos conselhos de fábrica (dispositivo pulsante em cada local de trabalho) ou "comissões de fábrica”, no Brasil, conforme Athayde (1988), uma tradição de lutas em que o militante político italiano A. Gramsci (1981) se destaca e que muita influência teve sobre Oddone. O segundo era a incompreensão de uma grande parte do movimento sindical acerca da articulação entre as lutas reivindicatórias tradicionais e a luta pela saúde nos locais de trabalho - algo que a nosso ver não se desenvolveu como merecia. O terceiro, a seu ver (CAPISTRANO FILHO, 1986, p. 8), era a fragilidade da "consciência ecológica" presente nos movimentos sindicais e entre intelectuais, o que dificultava a construção "da aliança do mundo do trabalho com o mundo da cultura e da ciência" (a propósito, quanto à realidade italiana, ver BARCA, 2010). Por fim, o quarto era o então raquitismo da democracia que fazia com que os movimentos de trabalhadores fossem tratados de forma repressiva e com uso de violência - haveria hoje que buscar melhor compreensão de nossa situação.

Este breve, mas vigoroso, balanço nos inspira a retomar a contribuição de Oddone e parceiros do MOI, buscando refletir sobre como esse patrimônio pode servir de instrumento no presente, com vistas ao desenvolvimento da capacidade de transformação das situações de trabalho no Brasil, renovando o campo da Saúde do Trabalhador.

Em um primeiro momento, faz-se um balanço das formas de incorporação do legado do MOI nos estudos e nas práticas de Saúde do Trabalhador. A seguir, apresenta-se a experiência de construção de cartografias de riscos industriais desenvolvida em região do sudeste da França, com sua assessoria. Na terceira parte, o ensaio trata da concepção de "comunidade científica ampliada" e suas derivações. Ao final, discute-se a técnica de "instrução ao sósia" enquanto instrumento eficaz tanto para a reapropriação, pelos trabalhadores, de suas estratégias de ação no trabalho, como para desenvolvê-las.

\section{O Modelo Operário Italiano e seu legado}

Para uma análise do legado do MOI - em especial a influência de Oddone - no Brasil, temos como base um conjunto de publicações que serão apresentadas e exploradas. Entretanto, não obstante os estudos aqui realçados, afirmamos que, de fato, este patrimônio não pode ser totalmente apreendido pela consulta à literatura especializada. É fato, consoante Kuchenbecker (1992), que no Brasil os trabalhadores e seus sindicatos têm pouca tradição de iniciativas a respeito das questões de saúde, considerando em especial as situações concretas de trabalho. Somente a partir da década de 1980 - quando se pode detectar a influência do MOI - as condições dos ambientes de trabalho e de saúde dos trabalhadores passaram a ser matéria de interesse sindical.

Lima et al. (2009) já realçaram que é inegável a importância da Itália no processo brasileiro de cons-

\footnotetext{
${ }^{6}$ Registramos aqui o evento em sua homenagem que ocorreu em novembro de 2012, na Universidade de Turim, sobre o tema: "Desafios atuais, passado, futuro: o percurso de Ivar Oddone", que teve a participação de uma das autoras deste ensaio.

${ }^{7}$ Também traduzido e publicado em alemão e japonês.
} 
trução do direito à saúde. Também foi propício à disseminação das ideias registradas no MOI o momento político vivido no Brasil ao final da década de 1970, quando os sindicatos conseguiram sair da clandestinidade e aliar-se abertamente ao movimento de reconstrução da democracia. Não por acaso, a retomada do cenário político pelo movimento sindical inicia-se no chamado ABC paulista ${ }^{8}$, a partir das grandes greves de 1978 nas indústrias automobilísticas. Houve um esforço de romper com a camisa de força que a ditadura militar impunha à "ordem e à segurança”, após um período surdo de acumulação de forças que ocorreu dentro das fábricas e dos locais de trabalho (inclusive no campo), caracterizado por diferentes formas de luta (ATHAYDE, 1988; SADER, 1988). No campo sindical, a partir de uma articulação de vários setores do movimento, em 1978 foi criada a Comissão Intersindical de Saúde e Trabalho (Cisat), em São Paulo, a qual dois anos depois tornou-se o Diesat, de caráter nacional. A criação dos Programas de Saúde do Trabalhador inaugurava a participação conjunta de sindicatos e serviços públicos de saúde na investigação das condições de saúde no trabalho. Finalmente, na Carta Constitucional de 1988 foram regulamentadas, pela Lei $n^{\circ} 8.080$, as atribuições do Estado brasileiro para intervir nos espaços de trabalho (MINAYO-GOMEZ; THEDIM-COSTA, 1997; LACAZ, 1997).

A primeira contribuição do MOI foi aquela que se configura no mapeamento dos riscos nos ambientes de trabalho. Mapa de Riscos se disseminou por vários pontos do planeta, chegando ao Brasil no início da década de 1980. Existem distintas versões quanto à sua introdução no Brasil. Uma delas atribui tal feito às áreas sindical e acadêmica, através de figuras como David Capistrano Filho, Mário Gawryzewski, Hélio Baís Martins Filho, assim como do Diesat. Outra atribui à Fundação Jorge Duplat Figueiredo de Segurança e Medicina do Trabalho (Fundacentro) a difusão do mapa de riscos no país (MATTOS; FREITAS, 1994, p. 252).

Conforme lembraram Vasconcelos e Lacomblez (2005), o Mapa de Riscos é baseado na constatação de Oddone de que:

A ciência tradicional (a "dominante") define como objeto de observação o homem e o seu meio técnico. O seu objetivo é, sempre, uma medida objetiva que obtém graças a um método analítico e à utilização de instrumentos emprestados pelos físicos e pelos químicos, por um lado, e pelos médicos e psicólogos por outro. Essa abordagem tradicional comporta a decomposição e a medida, tanto do meio (no sentido restrito do termo) como do homem. O primeiro é decomposto em elementos simples (microclima, poeiras, gazes, fumos) e o segundo - considerado apenas do ponto de vista físico - é reduzido a dados antropométricos, a elementos objetivos. (ODDONE; RE; BRIANTE, 1981, p. 45)

A partir daí, o novo modelo científico que acabou por se impor a Oddone, produzido pela experiência dos homens, caracterizava-se, pelo contrário, por uma abordagem global dos problemas e pela formulação assumida de juízos de valor. Visava transformar o meio de trabalho em benefício do homem, enquanto que o modelo tradicional apenas procurava conhecê-lo (parcialmente). Propõe então consignar um novo objetivo à investigação médico-psicológica e privilegiar não a medida, mas a avaliação, não os instrumentos mecânicos, mas o julgamento dessa nova entidade que era o grupo homogêneo de trabalhadores, enquanto portador de uma experiência validada coletivamente de uma forma sincronica e diacronica. E como o método não é autónomo e é filho das hipóteses que são colocadas, a via metodológica construída passou pela "competência de utilização" comum a todos, pelo material cognitivo mnemotécnico ligado à linguagem histórico-natural, por aquilo que se poderia definir como “aquilo que não podemos não saber” e pelas perguntas: "Que imagens vêm ao espírito, por associação, quando um sujeito escolhe uma casa? Quais vêm quando pensa numa fábrica? Quais, quando pensa em fadiga?’. Daqui emerge um roteiro que serve de suporte ao mapeamento dos quatro grupos de fatores nocivos: "a casa, que faz lembrar: temperatura, iluminação, ruído, ventilação, humidade (1ำ grupo); a fábrica: poeiras, gases, fumos, vapores (2o grupo); a fadiga, dois tipos fundamentais de fadiga: a tradicional, devida à atividade física (3o grupo) e outras formas infinitas de fadiga devidas a causas que não a atividade muscular, por exemplo, monotonia, ansiedade, repetitividade, ritmos excessivos, responsabilidade (4o grupo)." (VASCONCELOS; LACOMBLEZ, 2005, p. 41)

Assim, o MOI constitui também importante referência teórico-metodológica, sobretudo no que se refere às intervenções nos ambientes de trabalho sob o protagonismo dos trabalhadores em aliança com profissionais de saúde (RUZZENENTI, 1990). Dentre as experiências no Brasil, destacam-se alguns estudos, como o de Facchini, Weiderpass e Tomasi (1991), realizado em empresa do ramo químico-farmacêutico. Para esses autores, a classe trabalhadora teve a oportunidade de lançar mão dessa metodologia na defesa de sua saúde como estratégia para desvendar a intimidade do processo de trabalho, recolocando-o como centro da vida social. Esse tipo de ação operária fez com que os locais de trabalho ressurgissem como espaço importante de promoção de novas relações sociais e de luta pela saúde.

${ }^{8}$ Municípios de Santo André, São Bernardo do Campo e São Caetano, além de Diadema. 
Para Machado (1997), os princípios do MOI foram interpretados à luz do neopreventivismo do movimento sanitarista brasileiro e incorporados nas experiências de desenvolvimento de ações de vigilância em saúde do trabalhador no interior do sistema de saúde na década de 1980. Esse processo aconteceu com forte cunho sindical e acadêmico, generalizado pela Lei Orgânica de Saúde (BRASIL, 1990), base da Reforma Sanitária brasileira e do Sistema Único de Saúde (SUS).

Da mesma forma, outro estudo (MACHADO; NETZ, 2006) desenvolvido com a perspectiva de vigilância em saúde do trabalhador, em conjunto com o sindicato dos bancários, realça o MOI como referência teórica e metodológica. Os autores destacam o princípio de que para intervir é preciso conhecer, mas que as informações relativas às condições de trabalho e à saúde devem ser validadas com a participação dos trabalhadores a partir de seus locais de trabalho. Entre os resultados alcançados, relatam aumento da participação dos trabalhadores nas lutas por melhores condições de trabalho, maior eficácia e efetividade nas ações desenvolvidas pelo sindicato e, fundamentalmente, mais visibilidade social aos problemas de saúde enfrentados por esse grupo. Ademais, observam que este tipo de procedimento torna as negociações coletivas com as empresas mais qualificadas.

Flor e Kirchhof (2006) desenvolvem o argumento de que, apoiadas nos preceitos do MOI, sensibilizaram os profissionais de saúde de uma unidade de terapia neonatal quanto à exposição à radiação ionizante. As autoras sublinham que este modelo é um método de geração de conhecimento para a ação. Ou seja, realçam que a preocupação fundamental é transformar as condições de trabalho, com vistas ao bem-estar e à proteção da saúde dos trabalhadores, a partir de uma abordagem detalhada do processo de trabalho.

De acordo com Sato (1996), a explicitação de uma proposta de atuação nos locais de trabalho a partir do conhecimento dos trabalhadores não é uma prática nova, mas merece ser discutida. Para a autora, apesar do MOI ter inspirado a obrigatoriedade de elaboração do Mapa de Riscos Ambientais pelas Comissões Internas de Prevenção de Acidentes - Cipas (BRASIL, 1995), é necessário aprofundar a discussão acerca da epistemologia que combina conhecimento prático e conhecimento científico.

Outro exemplo de estudo que adotou o MOI como referência teve como objetivo verificar a intoxicação por mercúrio metálico em trabalhadores de uma indústria em São Paulo (ZAVARIZ; GLINA, 1993). Valendo-se da elaboração de mapa de riscos, as autoras abordam a fábrica como um todo, destacando-se nesse processo a avaliação subjetiva por parte do grupo dos trabalhadores, validada segundo a classificação dos grupos de riscos.
Facchini, Weiderpass e Tomasi (1991, p. 400) registram o que entendem por limitações, especialmente as que consideram "de natureza analítica e prende-se à própria característica dos estudos descritivos, baseados em informações qualitativas". Facchini e colaboradores, seja no texto anterior, seja em outro (FACCHINI et al., 1997), chamam a atenção para as novas formas de utilização de mapas de riscos, que têm como fonte de inspiração o MOI. Para eles, trata-se de um modo eficaz de representação dos riscos ocupacionais, constituindo-se em um elemento básico para a estruturação de planos de prevenção dos danos à saúde dos trabalhadores. Por exemplo, na pesquisa-intervenção junto ao Sindicato da Indústria de Alimentação do Município de Pelotas-RS, Fassa e Facchini (1992) fizeram uso de elementos do MOI e do que denominam Jogo Dramático, cuja fusão em seu entendimento teria ajudado a "sistematizar a percepção dos trabalhadores sobre o processo de trabalho, suas cargas e suas repercussões na saúde, assim como as proposta para controlá-las" (p. 13).

Neste sentido, a despeito de aspectos relacionados à representação de riscos que precisam ser discutidos mais detalhadamente nos ambientes de trabalho, ao lado de outros que deveriam ser incorporados - como as questões de gênero (BRITO, 1997) -, a legislação que estabelece a obrigatoriedade da elaboração de mapas de riscos pelas empresas significou um avanço importante para o país. Nesta linhagem de estudos que lançam mão do mapa de riscos como ferramenta metodológica de ação e intervenção nos ambientes de trabalho, pode também ser citada a experiência de Hökerberg et al. (2006), realizada em um hospital público no município do Rio de Janeiro. Os autores afirmam ter colocado em prática alguns princípios que estariam na base da concepção do MOI, enfatizando o ângulo de análise sobre aspectos educativos da experiência de Oddone e equipe: socialização, integração e participação. Em seu entendimento, o processo de elaboração do mapa propiciou vivências como as pretendidas pelo MOI, ao demonstrar, por exemplo, o peso da reivindicação coletiva na promoção de mudanças contra as quais as chefias se opunham. O mais relevante teria sido a reflexão suscitada nos trabalhadores e a mudança de perspectiva de passivos e reclamantes para atores com capacidade de interferir no ambiente de trabalho. Essas reflexões geraram tanto descobertas sobre a natureza do trabalho executado, quanto tensões, insatisfações e angústias que corresponderiam a símbolos pouco visíveis aos olhos na linguagem do mapa, mas reconhecidamente essenciais para todos os envolvidos neste percurso.

Contudo, Mattos e Freitas (1994), ao analisarem os limites da metodologia de mapas de riscos no Brasil, observam que a investigação e a negociação 
das causas da nocividade do trabalho só teriam sucesso efetivo quando acompanhadas das condições objetivas para o exercício real da democracia e da cidadania nos ambientes de trabalho, com livre possibilidade de organização, contratação coletiva de trabalho, liberdade e autonomia sindical, conferindo a ambas as partes as condições propícias para o diálogo e o entendimento acerca da organização do trabalho e da produção.

Segundo Benatti e Nishide (2000), o processo de estudo e elaboração de mapa de riscos deve acontecer não só para atender a legislação vigente (NR5), mas principalmente para, de fato, prevenir, controlar e eliminar os riscos de acidentes ocupacionais, o que também significa acompanhar os resultados após a sua implantação, incorporando a visão dos trabalhadores.

Vale também mencionar o estudo de Souza et al. (2003), em que se destaca a utilização do conceito de "validação consensual". Trata-se de discussões e reflexões coletivas a respeito do trabalho, seus possíveis riscos e nocividade, lançando mão da experiência do trabalhador e vislumbrando as possibilidades de transformação do trabalho a partir da confrontação entre as observações espontâneas e as críticas de cada sujeito envolvido. A validação consensual refere-se ao julgamento coletivo, pelo qual o grupo legitima a experiência de cada um relativa às condições de trabalho. As autoras insistem: ao se incorporar o saber dos trabalhadores, suas experiências e vivências, privilegiando-as, a produção de conhecimentos se torna mais rica e com maior potencial de intervenção. Portanto, como afirmam Sato, Lacaz e Bernardo (2006), o MOI teve e tem ainda hoje grande influência, no Brasil, nas escolhas metodológias para identificação dos problemas de saúde no trabalho e para a definição de prioridades de atuação tanto nos órgãos sindicais, como nos serviços de Saúde Pública.

Poderíamos, ainda, afirmar que os fundamentos do MOI foram parcialmente incorporados e formalizados como parte do patrimônio dos trabalhadores - sua linguagem, valores e ideologia - embora de forma não linear e progressiva. Por exemplo, o princípio basilar de que "a saúde não se vende, nem se delega, se defende" até hoje nunca esteve efetivamente incorporada, ao contrário, vemos importantes recuos. Não obstante, pode-se considerar que hoje há um debate mais qualificado a respeito da relação entre saúde e trabalho, pois conforme Paiva e Vasconcelos (2011, p. 385):

o modelo operário italiano nasceu com a proposta de modificar conceitos e romper com o paradigma no qual a defesa da saúde deveria ficar a cargo das instituições oficiais.

É preciso destacar a importância epistemológica do MOI, pois este dispositivo de lutas tem como uma de suas bases um "modelo operário de produção de conhecimento" (BRITO, 2004). Nesta perspectiva, busca-se colaborar para fortalecer a defesa das classes trabalhadoras e populares, articulada em princípios e conceitos (cuja definição remetemos aos textos aqui referenciados) como: conhecer e transformar; validação consensual; não delegação; grupo operário homogêneo; valorização da experiência e da "subjetividade" operária; defesa da saúde nos locais de trabalho e socialização do conhecimento. Estes são parte de uma herança do movimento internacional de trabalhadores que serviu de base à concepção e à consolidação do campo da Saúde do Trabalhador no Brasil, fecundando suas formulações no âmbito político e acadêmico.

\section{A cartografia dos riscos industriais como um sistema complexo integrador de experiências}

De acordo com Oddone (1999), milhares de "mapas brutos" de riscos foram feitos na Itália, entre os anos 1960 e 1970, por operários, estudantes, médicos e psicólogos engajados nas lutas pela saúde. Esses "mapas brutos" - brutos porque à espera de uma elaboração formal, no estado de um conhecimento ainda analógico - eram desenhos elaborados para representar as condições de trabalho, valorizando a experiência/saber dos trabalhadores, de acordo com o princípio tão caro da "não delegação". A cooperação entre os atores envolvidos nessas lutas baseou-se nesse princípio através de processos de validação dos conhecimentos, sejam empíricos, sejam científicos, por parte dos "grupos homogêneos". Enfim, nas palavras de Oddone (2007, p. 52), "essa Experiência 'bruta', 'analógica', coloca ao investigador o problema de como a recolher, ou melhor, de como a "construir" com o trabalhador, para a tornar digital, ou seja, transmissível aos outros”.

Essas ideias nem se restringiram à Itália, nem se tornaram obsoletas, nem desapareceram com o descenso das lutas operárias. Elas desencadearam, por exemplo, uma experiência importante na região de Bouches-du-Rhône, próximo à cidade de Marseille, que concentra parte das indústrias da França (ANDÉOL, 1981). Iniciada ao final dos anos 1970, tutelada no início pelas Mutualitès ${ }^{9}$ da região Bouches-du-Rhône,

\footnotetext{
${ }^{9}$ Cuja origem se inscreve na tradição internacional do movimento mutualista (iniciado na Inglaterra, século XXVIII, as Friendly Societies) caracterizada por um esforço de socorro mútuo, autônomo, entre trabalhadores. À base de cotização livre, buscava-se reforçar laços de solidariedade para fazer face aos riscos sociais a que estavam sujeitados, em particular à doenca, à velhice e à morte.
} 
ela, desde então, contou com a assessoria direta de Ivar Oddone. Sua evolução ao longo do tempo configurou-se com a perspectiva de construção de uma cartografia dos riscos industriais considerados, em princípio, elimináveis, culminando com a criação de um Sistema de Informação Concreta (SIC), um sistema complexo integrador de experiências.

Cartografar, neste caso, envolve uma "entrevista" inicial com os trabalhadores para o registro de informações individuais e sobre os postos de trabalho em fichas que passam a ser informatizadas (VASCONCELOS; LACOMBLEZ, 2005). Esse registro de informações individuais é feito por ficha composta de 4 itens: (i) identificação do trabalhador; (ii) identificação do posto de trabalho; (iii) os riscos e os agentes agressores presentes; (iv) chamada "folha de acompanhamento", a quarta parte é destinada à coleta de informações não codificadas sobre o trabalhador e suas condições de trabalho, permitindo observações acerca de questões não previstas.

Conforme Vasconcelos e Lacomblez (2005), a ficha do posto de trabalho representa a base da anamnese ambiental a ser utilizada para estabelecimento de nexos entre danos à saúde e ambiente. Vale chamar a atenção que, para a identificação do posto, são considerados: os contextos espaciais concretos em que se trabalha; o que o trabalhador faz; e as características específicas (positivas ou negativas) do processo em análise. Esses três elementos são tratados pelas seguintes expressões: " 2 x 2" (com referência ao entorno do posto de Trabalho), "OQF" (que significa "o que se faz") e "especificidade local".

O conjunto de dados coletados alimenta o Painel Municipal de Riscos, que é composto por uma carta topográfica do município com a identificação dos locais onde há risco e informes relativos aos riscos prioritários: número de pessoas expostas com registro no SIC, estimativa do conjunto de pessoas expostas a cada um desses riscos, número de pessoas acometidas por determinados agravos de acordo com os registros do SIC, estimativa da quantidade de trabalhadores acometidos pelos mesmos agravos. Este painel é atualizado periodicamente e viabiliza e enriquece o diálogo entre profissionais de saúde, trabalhadores e governo local (RE et al., 2006), assegurando uma grande difusão dos dados produzidos.

A originalidade do trabalho realizado pode ser assim resumida:

- a "memória dos trabalhadores", isto é, a descrição que fazem de seus postos de trabalho e das exposições a riscos, é ponto fundamental para a construção das informações. Aí se situa a técnica das Instruções ao Sósia ${ }^{10}$, suporte metodológico que permite colocar-se sempre face ao homem produtor enquanto sujeito rico de uma experiência que o especialista não possui. Considera a Experiência"11 "territorializada" (ODDONE, 2007);

- a "escala de consciência refletida". Segundo o autor (p. 53): "não se pode integrar os especialistas a não ser com base numa escala de consciência refletida (que encontra no primeiro patamar o trabalhador produtor e o médico generalista)", o que seria garantido pela superação do nível individual da experiência do especialista singular;

- a Gadeca (galeria de casos) e o Gadepost (galeria de postos): os dados sobre adoecimentos alimentam as duas galerias. A Gadeca objetiva estabelecer relações entre saúde e trabalho através da rigorosa alimentação do banco de dados gerado (a galeria de casos conhecidos por um grupo de médicos generalistas que trabalham no SIC), assim como fomentar a cooperação entre profissionais que atuam na área (RE et al., 2006). Na Gadepost são representados os estabelecimentos industriais onde ao menos um posto de trabalho nocivo (“a sanear") é identificado e classificado, de acordo com sua gravidade, como risco comprovado ou altamente provável. As galerias auxiliam os profissionais de saúde na identificação e confirmação de adoecimentos relacionados ao trabalho através da comparação com casos similares já registrados;

- comitê de saneamento: trata-se de um "conjunto complexo de sujeitos, integrados ao nível do conhecimento dos conteúdos, por via dos instrumentos procedimentais de integração" (ODDONE, 2007, p. 53), que lhes possibilita superar o nível individual de responsabilidade. O Painel Municipal de Riscos apresenta uma síntese desses dados de forma atualizada, indicando: (a) onde estão os riscos prioritários, (b) quantos estão a eles expostos, (c) quantos são os trabalhadores lesionados, (d) um Gadepost saneado.

É importante assinalar que o foco deste dispositivo é a produção industrial e que a noção utilizada é a de "riscos elimináveis". Outras situações não são, para já, explicitamente visadas, em especial as que envolvem questões de saúde mental, em que a

\footnotetext{
${ }^{10}$ Registre-se que já não recorrem de modo sistemático a esta técnica, embora talvez seja possível dizer que o "espírito" se mantenha, na forma de reunir dados.

${ }^{11}$ Aqui se manteve o conceito em maiúsculas, como o autor o fez no artigo citado.
} 
apreensão dos "riscos" (ou, como preferimos, as adversidades) exigem análises que considerem particularmente as estratégias, as defesas e as reações dos trabalhadores. Entretanto, enfrentar as nocividades próprias à produção industrial, e que podem de fato ser eliminadas, é fundamental, assim como dispor de ferramentas para eleger prioridades de ação, sobretudo se esta eletividade considera o saber prático dos trabalhadores. Interessante é que a cartografia dos riscos assim construída, mesmo chegando a uma representação territorial, geográfica, parte de relatos que correspondem à sua primeira referência.

Sem esquecer as diferenças entre os dois contextos (França e Brasil), ao apresentar sucintamente esta experiência do SIC, busca-se evidenciar outro modo de atualização dos princípios do MOI. A estratégia de vigilância dos riscos industriais implementada do outro lado do Atlântico combina o uso de recursos tecnológicos modernos (informática) com um olhar situado sobre o processo produtivo, considerando o saber do trabalhador. O estabelecimento de um diálogo entre esta experiência e as estratégias de Vigilância em Saúde do Trabalhador propostas no Brasil nos parece pertinente e enriquecedor.

\section{Comunidade Científica Ampliada, Dispositivo Dinâmico de Três Polos e Comunidade Ampliada de Pesquisa}

Apesar de com frequência usarmos apenas o nome de Oddone, na verdade o extraordinário intelectual do campo da Saúde do Trabalhador e da Psicologia do Trabalho, em suas dimensões epistemológica, teórica, metodológica e técnica, lidera um coletivo, uma verdadeira comunidade em ação. A rigor, outra ideia originária do MOI e que é partilhada não somente no campo da Saúde do Trabalhador, mas também na área mais ampla da Saúde Pública no Brasil é a concepção de "comunidade científica ampliada" (CCA). A partir do enorme destaque e da leitura crítica desenvolvidos por Schwartz (1988, 1996), Brito e Athayde (2003) formularam um dispositivo com a nova qualificação de Comunidade Ampliada de Pesquisa (CAP) ${ }^{12}$, no qual circula uma comunidade dialógica de pesquisa (FRANÇA, 2007). Vale ressaltar que a mudança da denominação CCA para CAP, retirando-se o vocábulo "científica", buscou evitar uma falsa compreensão de que Oddone e sua equipe buscariam transformar os trabalhadores em cientistas ou enquadrar a produção de saberes em uma perspectiva científica que impõe limites à possibilidade de trabalhar com a experiência, registrando que o que se pretendia ampliar era a capacidade investigativa de todos. Na verdade, a sinergia entre diferentes saberes frente a problemas concretos colabora decisivamente para a mútua crítica e desenvolvimento, em uma dinâmica virtuosa. Além disso, está presente também a sinalização de Schwartz (2000) que aponta para a necessidade de estar atento às mudanças, à emergência de novos atores sociais, como nos movimentos de desempregados.

Este dispositivo metodológico - CAP - vem sendo desenvolvido no Brasil desde a experiência do Programa de Formação em Saúde, Gênero e Trabalho nas Escolas, iniciado no final dos anos 1990 (BRITO; ATHAYDE, 2003; BRITO; ATHAYDE; NEVES; 2003). A história desse dispositivo-conceito, no âmbito das publicações nacionais, remete a alguns estudos sobre o Programa de Formação que conjugou pesquisas científicas e formação de trabalhadores de escolas públicas tendo como foco as relações saúde-trabalho nas situações concretas de trabalho que desenvolvem. Tinha por objetivo principal compreender $\leftrightarrow$ transformar as relações entre o trabalho e os processos de saúde-doença, associando profissionais de pesquisa e os protagonistas do trabalho em análise.

Pode-se então verificar que constituir uma CAP e desenvolvê-la, conforme asseguram Brito e Athayde (2003), diz respeito à experimentação de um modo de pesquisar-interferir através da confrontação heurística entre os diferentes saberes (sejam os de tipo científico-disciplinar-acadêmico, sejam os investidos na prática). Pretende-se, adotando esse paradigma, desenvolver uma forma original de pesquisa $\leftrightarrow$ intervenção na linha do que Oddone e parceiros designaram "pesquisa não ritual" (no sentido de que ela contestaria os métodos da pesquisa tradicional).

Vale lembrar ainda a influência do MOI e da postura epistemológica que lhe é subjacente na atual formulação da Política Nacional de Humanização (PNH) do Ministério da Saúde, o que se evidencia em diversas publicações, sejam acadêmicas ou do próprio Ministério (SKAMVETSAKIS, 2006; MORI; SILVA; BECK, 2009; BRASIL, 2006). Esses autores referem-se, efetivamente, ao conceito de CAP como uma maneira de se construir coletivamente a reflexão a respeito do fazer em saúde no cotidiano dos serviços, fundamentando-se no diálogo permanente com os trabalhadores.

\footnotetext{
${ }^{12}$ Remetemos a um dos livros de Schwartz (1986) em sua crítica à denominação Comunidade Ampliada de Pesquisa, procurando desenvolver o que ali se revelava, o que posteriormente o autor (1996) apresentou como o "Dispositivo Dinâmico de Três Polos" (DD3P). Assim como remetemos a Brito e Athayde (2003) a apresentação da configuração do DD3P que se apresentou como "Comunidade Ampliada de Pesquisa".
} 


\section{A instrução ao sósia como instrumento de desenvolvimento da experiência}

Como já demonstrado, a proposta e o método de mapeamento de riscos na sua forma inicial na Itália foram largamente utilizados e divulgados no Brasil, passando por diversas reformulações. Já a proposta da cartografia (configurada no SIC), não. Essa riqueza presente neste patrimônio - que está sistematizada em Oddone, Re e Briante (1981) no livro inicialmente publicado na Itália em 1977 sob o título Experiência operária, consciência de classe e Psicologia do Trabalho - passou a circular entre nós somente a partir de meado dos anos 1990. No interior de uma nova perspectiva de ação-investigação, a questão da experiência toma um lugar central (ODDONE, 2007; CORNU, 2001; SCHWARTZ, 1988).

Segundo o próprio Oddone (2007), inicialmete os trabalhadores eram, para ele, apenas informantes, e o problema estaria na forma de "coletar" suas experiências. Em seguida, como já o dissemos, eles tornaram-se elemento central: os trabalhadores singulares que compõem um grupo que corresponde a um dado posto de trabalho, "territorializado", isto é, identificado em um contexto preciso enquanto lugar único, que não se pode repetir. Ou seja, em vez de uma experiência "bruta, analógica", cujo problema estaria em como "coletá-la", Oddone avança no sentido de perceber que, na verdade, trata-se de uma experiência a ser construída como protagonista do trabalho em análise, para torná-la digital, "transmissível aos outros" (ODDONE, 2007, p. 57). Trata-se então de uma experiência do modo de produzir que pode tornar-se, no conhecimento do trabalhador, uma Experiência que permite acelerar e enriquecer o processo de produção da própria experiência do trabalho. Ela determina a formação do know-how da empresa. É dessa forma que Oddone e seus parceiros elegem a experiência enquanto fonte tanto para o equacionamento do adoecimento profissional, como para o encaminhamento das lutas pela transformação do trabalho.

Quase dez anos depois dessa experiência do MOI realizada no final dos anos setenta, quando na Itália a força das lutas operárias perdiam terreno, na França, como vimos, Oddone passa a acompanhar uma nova experimentação na região de Bouches-du-Rhône. Trabalhando na mesma região, Yves Schwartz (1988) deu um novo sopro de vida com suas análises, em seguida propondo o que vai denominar Ergologia (SCHWARTZ, 1996).

Se retomarmos os problemas levantados por Capistrano Filho (1986), podemos considerar que uma importância capital do patrimônio de Oddone e parceiros foi uma mudança no modo de construir os problemas para a ação-investigação em situação de trabalho. Oddone, Re e Briante (1981) perceberam que, antes da intervenção dos especialistas, os operários já faziam uma intervenção sobre o seu trabalho, já exerciam uma crítica à organização do trabalho. A questão que enfrentavam era como trazer essa potencialidade e riqueza, essas estratégias de intervenção e de luta para o centro das pesquisas e da formação sobre as situações de trabalho, colaborando decisivamente para a transformação social. Eles salientaram que cada operário construía planos - no sentido de uma das orientações da Psicologia Cognitiva de então, liderada por Miller, Galanter e Pribam (1960) - para agir no seu trabalho; e esses planos, por sua vez, estavam profundamente ligados a uma experiência coletiva, de um patrimônio comum que construíam na medida em que se defrontavam com os problemas concretos de seu trabalho, de como lidar com o sistema técnico, seus defeitos e variabilidades, mas também de como lidar com a relação com seus colegas, com a hierarquia e com o movimento sindical - ou seja, com todo o sistema sociotécnico.

Para pôr em evidência o "plano-programa" que organiza as ações do trabalhador, Oddone, Re e Briante (1981) passaram a elaborar a técnica das instruções ao sósia, precisando:

é evidente que com este método não é o comporta-
mento real e total do indivíduo que recolhemos, mas
a sua imagem, o seu duplicado, isto é, a representação
que ele faz do seu próprio comportamento. (p. 57)

Portanto, o princípio foi o de fazer com que esses planos, essas estratégias fossem explicitadas, socializadas e discutidas, de modo que essa ação-reflexão coletiva produzisse e desenvolvesse uma experiência de reapropriação de sua capacidade de intervenção, avançando. Dessa forma, tentaram ultrapassar o fato de que, muitas vezes, os trabalhadores tendem a falar de sua ação no trabalho de uma maneira idealizada, como um manual prescritivo de como se deveria trabalhar e ser militante sindical, não trazendo as contradições, os desafios, os desconfortos produzidos pelo descompasso entre a prescrição e o trabalho que efetivamente se realizou. A técnica permite ainda contornar outro grande problema para a investigação em comum: os obstáculos à entrada dos profissionais de saúde (intelectuais orgânicos da classe, conceito de Gramsci, 2006) nos locais do trabalho.

A técnica de instrução ao sósia vai então servir para esse objetivo de produzir uma confrontação do trabalhador com os seus próprios planos, possibilitando uma crítica a tais planos e sua transformação, aperfeiçoando as estratégias de intervenção sobre as situações de trabalho. Consiste em gerar uma situação em que o trabalhador aceite "fazer de conta" que outro trabalhador seja seu sósia (seu clone) e que 
supostamente iria substituí-lo no trabalho. A solicitação-orientação dada por Oddone ou parceiro era a seguinte:

Se existisse outra pessoa perfeitamente idêntica a você do ponto de vista físico, como você o instruiria para se comportar na fábrica com relação às tarefas, aos seus colegas de trabalho, à hierarquia e à organização sindical (ou outras formas organizativas) de forma que ninguém perceba que se trata de outro e não de você? (ODDONE; RE; BRIANTE, 1981, p. 57)

Ora, na medida em que o trabalhador se defrontava com um interlocutor com exigências distintas de um interlocutor-leigo, a situação se modificava, o trabalhador-instrutor se deslocava de seu lugar naturalizado. O seu colega, trabalhador-sósia, não ficava passivo no diálogo, ao contrário, exigia que as instruções fossem mais detalhadas, fazendo novas perguntas que introduziam a variabilidade, a sutileza, as nuances que cada trabalhador imprime não só ao realizar suas tarefas, mas ao travar suas relações com os meios de trabalho, os colegas e a hierarquia. Ao ser forçado a entrar nos detalhes, nas minúcias, o trabalhador ia se espantando com a complexidade de sua atividade, fazendo, neste processo, a crítica, a avaliação dos efeitos das escolhas que vinha fazendo em cada situação. Começa, portanto, a entrar em um processo de transformação das estratégias que utilizava no trabalho. Essa dinâmica era feita em grupo com diferentes trabalhadores, possibilitando que todo o coletivo se mobilizasse na reflexão acerca de sua própria experiência no trabalho. Um dado importante é que, como emergia com toda a força a dimensão subjetiva do trabalhar, a presença de debates de escolhas entre um modo de agir e outro, sepultava-se a concepção de uma mera passividade ou alienação frente à sua inserção e a dos companheiros no processo capitalista de produção.

A estratégia apresentada por Oddone, Re e Briante (1981) permite reconhecer que já existe uma "psicologia não escrita” construída na e pela atividade dos trabalhadores. A percepção deste patrimônio mantém-se fundamental, inclusive porque as novas tecnologias e formas de organização do trabalho cada vez mais envolvem a mobilização cognitiva, afetiva e social dos trabalhadores, assim como cada vez mais os profissionais da gerência são exigidos na prática a saber lidar com essa nova dinâmica que extrapola a simples burocracia e o puro despotismo e/ou manipulação. Para obter ganhos de produtividade e qualidade, alinhando-se aos objetivos de valorização de capital, as formas de gerenciamento têm que tomar outros rumos. Vale a pena citar uma posição política clara sobre essa estratégia de "recuperação da subjetividade" operada pelos especialistas a serviço do capital, algo que os autores italianos já manifestavam no seu manual Ambiente de Trabalho:
Rejeitamos a "recuperação da subjetividade", pois, seja quem for que a realize, esta pressupõe um sujeito externo aos homens expostos ou, de qualquer maneira, um sujeito que não coincide com o grupo dos homens expostos e portanto o exclui, às vezes raramente, não no momento da recuperação da experiência, mas certamente no aspecto que mais nos interessa, isto é, no da definição dos planos para reduzir o risco e, sobretudo, na responsabilidade das escolhas estratégicas de fundo. (ODDONE et al., 1986, p. 120)

Recuperação da subjetividade quer dizer delegar, e de outro lado a recuperação da subjetividade por parte dos técnicos é um fato antigo, representa a própria base do crescimento da medicina e da psicologia do trabalho. Os operários não têm a necessidade de que seja um técnico, mesmo de extrema esquerda, quem recupere a sua subjetividade, se nunca os técnicos (mesmo os de esquerda) têm necessidade de que a classe operária recupere sua subjetividade de técnicos em termos de escolhas de campo e em termos de escolhas diferentes dos modelos tradicionais, para utilizarem o saber. (ODDONE et al., 1986, p. 120)

Esta é uma indicação preciosa para os serviços em Saúde do Trabalhador que hoje se defrontam com os problemas de saúde envolvendo uma dimensão psicossomática cada vez mais acentuada e complexa. É o que atestam as pesquisas que, trabalhando com diferentes referenciais teóricos, abordam-nos enquanto estresse, burnout, sofrimento psíquico patogênico.

Oddone, Re e Briante (1981) fazem também um alerta importante no sentido de que, para poder mobilizar e desenvolver esse rico material que emerge na dinâmica das instruções ao sósia, é preciso que os próprios especialistas não orgânicos com o capital também reflitam que instruções dariam aos seus sósias. Portanto, trata-se de encaminhar um processo de produção de desenvolvimento também das práticas profissionais dos próprios pesquisadores e especialistas que operam na ótica da Saúde do Trabalhador, na medida em que também são levados a se confrontar com os planos e as estratégias que vêm utilizando no seu trabalho.

\section{Considerações finais}

Como dissemos, a proposta inicial do MOI que se denominou no Brasil "mapa de riscos" foi a que encontrou propagação no movimento sanitarista e sindical. Dissemos ser fato que a legislação que estabelece a obrigatoriedade da elaboração de mapas de riscos pelas empresas significou um avanço importante para o país. No entanto, trata-se de uma questão a ser avaliada hoje. Em que medida o avanço que significou nos anos 1990 teve continuidade? Seus princípios podem ter-se apagado, restando técnicas. 
Um leitor mais crítico deste ensaio poderia interpelar se a diferença de conjuntura política não tornaria inoportuna a utilização do patrimônio de Oddone e do MOI no momento histórico presente, visto que tal experiência se deu na efervescência social e política dos anos 1960-70 na Itália, sendo o Manual Ambiente de Trabalho publicado no Brasil nos movimentados anos de 1980. A experiência francesa que perdura seria localizada e exceção. Vivemos em todo o planeta uma crise da forma sindicato e da forma partido político, acompanhada por uma hegemonia ainda forte do ideário neoliberal e aparentemente uma maior dificuldade de articulação de práticas coletivas de resistência. De fato, não se trata de incorporar esse patrimônio tal e qual foi utilizado na Itália, ou como persiste em uma região francesa. Trata-se, isto sim, de verificar o potencial que apresenta este paradigma, na contemporaneidade, para produzir uma ação coletiva de defesa da saúde e afirmação da vida e/ou potencializar e ampliar as mobilizações já em curso, mesmo que fragilizadas, pontuais.

Além disso, há que interrogar as condições presentes e com o mesmo olhar desconfiado e crítico que Oddone e sua equipe tinham na sua época, inclusive com relação a posições como as de quem só apontava a questão da alienação, dada a exploração e dominação capitalistas. O ponto de vista aqui presente é que, se de fato as tradicionais formas de luta dos trabalhadores encontram-se fragilizadas e talvez obsoletas, ou menos visíveis suas forças, isso não significa que devamos endossar a hipótese de que agora a potência da vida está inteiramente sob controle. Aliás, documentos como o Rapport de la Comission d'Orientation du Plan National Santé Environnement ${ }^{13}$ (MOMAS; CAILLARD; LESAFFRE, 2004) apresentam fortes argumentos para dar sustentação ao trabalho já realizado (e que persiste) nesta linha da Saúde do Trabalhador. Assinala-se, por exemplo, que vários organismos internacionais, e em especial a Organização Internacional do Trabalho, admitem que os custos dos problemas de saúde relacionados ao trabalho estão próximos ou superam os $3 \%$ do PIB nos países industrializados.
Conforme a proposta da Ergologia, seria preciso ter "humildade epistemológica", trabalhando em nós o "desconforto intelectual” (SCHWARTZ, 2010) que emerge tanto pela dupla ignorância (de pesquisadores e protagonistas do trabalho em análise) de planos da realidade do trabalho, como das possíveis formas de luta, que talvez estejam em curso e não as reconheçamos. Assim, parece necessário apostar na premissa de que o papel dos profissionais do campo da Saúde do Trabalhador não é o de dirigir, guiar ou (re)criar o movimento dos trabalhadores, mas o de estar em campo, afetados pelo que está em curso, atentos aos (im)possíveis, ao que se está prestes a tornar-se, disponíveis como parceiros de uma ação coletiva para a transformação dos mundos do trabalho, afirmando a potência da vida.

O lugar de cada um nessa parceria não está dado a priori, mas é possível combinar alguns princípios éticos e epistemológicos que nortearão esse trabalho comum, como diria Schwartz (2000): a convicção de que todos os viventes têm capacidade normativa e que é pulsional a curiosidade e a busca de aprender com os outros. Mais do que uma teoria, Oddone e seus parceiros do MOI nos legaram com sua prática concreta a certeza de que isso não é humanamente impossível. Eles contribuíram para provar científica e politicamente a importância da criação de um novo paradigma para pensar a produção de conhecimento e a intervenção sobre as situações de trabalho intrinsecamente ligadas à transformação do trabalho e à afirmação da vida. Deixaram patente que a luta pela saúde não se faz apenas com a denúncia dos adoecimentos e acidentes produzidos nas situações de trabalho, mas também pela ampliação da capacidade de intervenção no seu trabalho e pelo modo como são engendrados movimentos coletivos. Como escreveu o poeta e revolucionário russo Maiakóviski (1983), concluindo seu poema $A$ Siergéi Iessiênin, amigo que se suicidara: "É preciso arrancar alegria ao futuro/ Nesta vida morrer não é difícil/Difícil é a vida e seu ofício”.

Assim, avaliar a importância de Oddone (e do MOI) envolve assumir a tarefa de melhor compreender e desenvolver o seu projeto de construir instrumentos para a ação (CLOT, 2010), de produzir vontade, mobilização e prática de transformação.

\section{Contribuições de autoria}

Todos os autores contribuíram igualmente e de forma significativa na elaboração e na revisão do manuscrito, assim como na aprovação da versão final.

${ }^{13}$ Relatório do plano nacional saúde meio-ambiente. 


\section{Referências}

ANDÉOL, M. La Mutualité des Bouches-du-Rhône. In: ODDONE, I.; RE, A.; BRIANTE, G. Redécouvrir l'expérience ouvrière: vers une autre psychologie du travail? Paris: Éditions Sociales, 1981. p. 251-258.

ATHAYDE, M. Processo produtivo, espaço educativo: um campo de lutas. 1988. 255 f. Dissertação (Mestrado em Educação de Adultos)-Centro de Educação, Universidade Federal da Paraíba, João Pessoa, 1988.

BARCA, S. Pão e veneno: reflexões para uma investigação sobre o ambientalismo do trabalho em Itália, 1968-1998. Laboreal, Porto, v. 6, n. 2, p. 10-18, 2010. Disponível em: <http://laboreal.up.pt/files/ articles/2010_12/pt/10-18f.pdf $>$. Acesso em: 4 set. 2013.

BENATTI, M. C.; NISHIDE, V. M. Elaboração e implantação do mapa de riscos ambientais para prevenção de acidentes do trabalho em uma unidade de terapia intensiva de um hospital universitário. Revista Latino-Americana de Enfermagem, Ribeirão Preto, v. 8, n. 5, p. 13-20, 2000.

BRASIL. Lei no 8.080, de 19 de setembro de 1990. Dispõe sobre as condições para a promoção, proteção e recuperação da saúde, a organização e o funcionamento dos serviços correspondentes e dá outras providências. Diário Oficial [da] República Federativa do Brasil, Brasília, DF, 20 set.1990. Disponível em: < http://www.planalto.gov.br/ccivil_03/ leis/l8080.htm>. Acesso em: 22 nov. 2013.

. Ministério do Trabalho e do Emprego. Secretaria de Saúde e Segurança do trabalho. Portaria n⿳o 25, de 29 de dezembro de 1994. Diário Oficial [da] República Federativa do Brasil, Brasília, DF, 15 dez. 1995. Disponível em: <http://portal.mte.gov.br/ data/files/FF8080812BE914E6012BEA44A24704C6 /p_19941229_25.pdf>. Acesso em 22 nov. 2013.

. Ministério da Saúde. Cartilha da PNH: trabalho e redes de saúde: valorização dos trabalhadores da saúde. Brasília: Ministério da Saúde; 2006.

BRITO, J. Uma proposta de vigilância em saúde do trabalhador com a ótica de gênero. Cadernos de Saúde Pública, Rio de Janeiro, v. 13, supl. 2, p. 141-144, 1997.

. Saúde do trabalhador: reflexões a partir da abordagem ergológica. In: FIGUEIREDO, M. et al. Labirintos do trabalho: interrogações e olhares sobre o trabalho vivo. Rio de Janeiro: DP\&A, 2004. p. 91-114.

BRITO, J.; ATHAYDE, M. Trabalho, educação e saúde: o ponto de vista enigmático da atividade. Trabalho, Educação e Saúde, Rio de Janeiro, v. 1, n. 2, p. 239266, 2003.

BRITO, J.; ATHAYDE, M.; NEVES, M. Y. Cadernos de textos: programa de formação em saúde, gênero e trabalho nas escolas. João Pessoa: Editora Universitária da UFPb, 2003.
CAPISTRANO FILHO, D. Apresentação. In: ODDONE et al. (Org.) Ambiente de trabalho: a luta dos trabalhadores pela saúde. São Paulo: Hucitec, 1986. p. 7-9.

CLOT, Y. Trabalho e poder de agir. Belo Horizonte: Fabrefactum, 2010.

CORNU, R. Education, savoir et production. Bruxelles: Éditions de l'Université de Bruxelles, 2001.

FACCHINI, L. A. et al. Ícones para mapas de riscos: uma proposta construída com os trabalhadores.

Cadernos de Saúde Pública, Rio de Janeiro, v. 13, n. 3, p. 497-502, 1997.

FACCHINI, L. A; WEIDERPASS, E.; TOMASI, E. Modelo operário e percepção de riscos ocupacionais e ambientais: o uso exemplar de estudo descritivo. Revista de Saúde Pública, São Paulo, v. 25, n. 5, p. 394400, 1991.

FASSA, A. C.; FACCHINI, L. A. Como discutir a saúde do trabalhador? A contribuição do Modelo Operário e do Jogo Dramático. Saúde em Debate, Rio de Janeiro, n. 34, p. 13-16, 1992.

FLOR, R. C.; KIRCHHOF, A. L. C. Uma prática educativa de sensibilização quanto à exposição a radiação ionizante com profissionais de saúde. Revista Brasileira de Enfermagem, Brasília-DF, v. 59, n. 3, p. 274-278, 2006.

FRANÇA, M. Uma comunidade dialógica de pesquisa. São Paulo: Fapesp/Educ, 2007.

GRAMSCI, A. Cadernos do cárcere. Os intelectuais; o princípio educativo; jornalismo. 4. ed. Rio de Janeiro: Civilização Brasileira, 2006. v. 2.

. Gramsci e os conselhos de fábrica. São Paulo: Brasiliense, 1981.

HOKERBERG, Y. H. M. et al. O processo de construção de mapas de risco em um hospital público. Ciência e Saúde Coletiva, Rio de Janeiro, v. 11, n. 2, p. 503-513, 2006.

KUCHENBECKER, R. O Modelo Operário Italiano trinta anos depois. Saúde em Debate, Londrina, v. 36, p. 48-50, 1992.

LACAZ, F. A. Saúde dos trabalhadores: cenário e desafios. Cadernos de Saúde Pública, Rio de Janeiro, v. 13, supl. 2, p. 7-19, 1997.

LIMA, R. C. et al. A construção do direito à saúde na Itália e no Brasil na perspectiva da bioética cotidiana. Saúde \& Sociedade, São Paulo, v. 18, n. 1, p. 118-130, 2009.

MACHADO, J. M. Processo de vigilância em saúde do trabalhador. Cadernos de Saúde Pública, Rio de Janeiro, v. 13, supl. 2, p. 533-545, 1997.

MACHADO, M. S.; NETZ, J. A. Vigilância da saúde do trabalhador no sindicato dos bancários de porto alegre: 
a operação de olho na saúde. Boletim da Saúde, Porto Alegre, v. 20, n. 1, p. 187-191, jan./jun. 2006.

MAIAKÓVSKI, V. A Sierguéi Iessênin. In: Poemas. 2. ed. São Paulo: Perspectiva, 1983. p. 109114.

MATTOS, U.; FREITAS, N. Mapa de risco no Brasil: as limitações da aplicabilidade de um modelo operário. Cadernos de Saúde Pública, Rio de Janeiro, v. 10, n. 2, p. 251-258, 1994.

MILLER, G. A.; GALANTER, E.; PRIBAM, K. H. Plans and the structure of behavior. New York: Holt, Rinehart and Winston, 1960.

MINAYO-GOMEZ, C.; THEDIM-COSTA, S. M. F. A construção do campo da saúde do trabalhador: percurso e dilemas. Cadernos de Saúde Pública, Rio de Janeiro, v. 13, supl. 2, p. 521-532, 1997.

MOMAS, I.; CAILLARD, J.-F.; LESAFFRE, B. Rapport de la Commission d'Orientation du Plan National Santé Environnement. Paris: Agence Française de Sécurité Sanitaire Environnementale, 2004. Disponível em: <http://www.ladocumentationfrancaise.fr/ rapports-publics/044000068/index.shtml>. Acesso em: 4 set. 2013.

MORI, E. M.; SILVA, F. H.; BECK, F. L. Comunidade Ampliada de Pesquisa (CAP) como dispositivo de cogestão: uma aposta no plano coletivo. Interface Comunicação, Saúde, Educação, Botucatu, SP, v. 13, supl. 1, p. 719-727, 2009.

ODDONE, I. Psicologia dell'organizzazione della salute. Psicologia della Salute, Milano, n. 1, p. 39-47, 1999.

. Reflexiones sobre el modelo obrero italiano.

Salud, Trabajo y Medio Ambiente, v. 2, n. 5, p. xxxx, 2007. Disponível em: <http://www.bvsst.org.ve/ documentos/pnf/salud_trabajo_y_ambiente_revista sindical.pdf>. Acesso em: 4 set. 2013.

ODDONE, I. et al. Ambiente de trabalho: a luta dos trabalhadores pela saúde. São Paulo: Hucitec, 1986.

ODDONE, I.; RE, A.; BRIANTE, G. Redécouvrir l'expérience ouvrière: vers une autre psychologie du travail? Paris: Éditions Sociales, 1981.

PAIVA, M. J.; VASCONCELOS, L. C. F. Modelo Operário Italiano: o surgimento do campo da saúde do trabalhador. In: VASCONCELOS, L. C. F.; OLIVEIRA, M. H. B. Saúde, Trabalho e Direito: uma trajetória crítica e a crítica de uma trajetória. Rio de Janeiro: Educam, 2011. p. 357-400.

RE, A. et al. A general physician-centred system for preventing environmental diseases. In: MEETING
DIVERSITY IN ERGONOMICS, PROC. IEA 2006 CONGRESS, 2006, Maastricht. Proceedings... Maastricht: Elsevier, 2006. 1 CD-ROM.

RUZZENENTI, M. A experiência no movimento sindical italiano na luta pela saúde dos trabalhadores. Caderno da CUT Jurídico e Relações Sindicais, São Paulo, n. 4, p. 44-47, 1990.

SADER, E. Quando novos personagens entram em cena. São Paulo: Brasiliense, 1988.

SATO, L. As implicações do conhecimento prático para a vigilância em saúde do trabalhador. Cadernos de Saúde Pública, Rio de Janeiro, v. 12, n. 4, p. 489-495, 1996.

SATO, L.; LACAZ, F. A.; BERNARDO, M. H. Psicologia e saúde do trabalhador: práticas e investigações na Saúde Pública de São Paulo. Estudos de Psicologia, Natal, v. 11, n. 3, p. 281-288, 2006.

SCHWARTZ, Y. Trabalho e ergologia. In: SCHWARTZ Y.; DURRIVE L. (Org.) Trabalho e ergologia: conversas sobre a atividade humana. 2. ed. rev. ampl. Niterói: EdUFF, 2010. p. 25-46.

A comunidade científica ampliada e o regime de produção de saberes. Trabalho \& Educação, Minas Gerais, n. 7, p. 38-46, 2000.

. Ergonomie, philosophie et exterritorialité. In: DANIELLOU, F. (Org.) Ergonomie en quête de ses principes. Toulouse: Octarès, 1996. p. 141-182.

. Expérience et connaissance du travail. Paris: Messidor/Éditions Sociales,1988.

SKAMVETSAKIS, A. Gestão compartilhada e humanização em saúde do trabalhador. Boletim da Saúde, Porto Alegre, v. 20, n. 2, p. 157-165, 2006.

SOUZA, K. R. et al. O desenvolvimento compartilhado de impressos como estratégia de educação em saúde junto a trabalhadores de escolas da rede pública do Estado do Rio de Janeiro. Cadernos de Saúde Pública, Rio de Janeiro, v. 19, n. 2, p. 495-504, 2003.

VASCONCELOS, R.; LACOMBLEZ, M. Redescubramonos na sua experiência: $\mathrm{O}$ desafio que nos lança Ivar Oddone. Laboreal, Porto, v. 1, n. 1, p. 38-51, 2005. Disponível em: <http://laboreal.up.pt/files/ editions/2005_12/laboreal_2005_12_pt.pdf $>$. Acesso em: 4 set. 2013 .

ZAVARIZ, C.; GLINA, D. M. R. Efeitos da exposição ocupacional ao mercúrio em trabalhadores de uma indústria de lâmpadas elétricas localizada em Santo Amaro, São Paulo, Brasil. Cadernos de Saúde Pública, Rio de Janeiro, v. 9, n. 2, p. 117-129, 1993. 